\section{$\underset{\substack{\text { hommes } \\ \text { \& migrations }}}{ }$}

\section{Hommes \& migrations}

Revue française de référence sur les dynamiques

migratoires

$1324 \mid 2019$

Religion et discrimination

\title{
Patrice Nganang, Empreintes de crabe
}

Paris, JC Lattès, 2018, 400 pages, 22,90 euros

\section{Mustapha Harzoune}

\section{OpenEdition}

1 Journals

\section{Édition électronique}

URL : https://journals.openedition.org/hommesmigrations/8935

DOI : 10.4000/hommesmigrations.8935

ISSN : 2262-3353

Éditeur

Musée national de l'histoire de l'immigration

Édition imprimée

Date de publication : 1 janvier 2019

Pagination : 176-177

ISBN : 978-2-919040-44-5

ISSN : $1142-852 X$

Référence électronique

Mustapha Harzoune, « Patrice Nganang, Empreintes de crabe », Hommes \& migrations [En ligne], 1324|

2019, mis en ligne le 01 janvier 2019, consulté le 08 janvier 2022. URL : http://

journals.openedition.org/hommesmigrations/8935; DOI : https://doi.org/10.4000/

hommesmigrations.8935 


\section{Patrice Nganang}

\section{Empreintes de crabe}

Paris, JC Lattès, 2018, 400 pages, 22,90 euros.

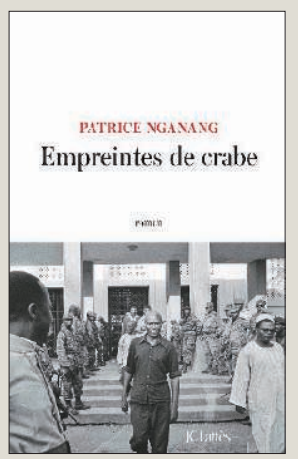

Nithap, respectable septuagénaire camerounais, s'en vient visiter son universitaire de fils. Installé aux États-Unis, Tanou est marié avec Angela et lui-même père de la petite Marie. Nithap ne devait rester que quelques jours mais, contretemps de santé, le voici installé pour plusieurs mois. Tanou espère mieux connaître son géniteur, car il semble que chez les Camerounais, et singulièrement chez les Bamiléké, on ne se parle pas trop entre père et fils. Tanou ignore pratiquement tout du passé de son père; lequel pourtant semble avoir besoin de «déverser son cœur». Un couple de voisins sera le réceptacle des souvenirs et des émotions du vieil homme.
Pour l'heure, face aux silences paternels,

Tanou «pleure», secrètement.

Empreintes de crabe est un roman touffu qui croise plusieurs récits et thèmes.

Centrale est l'histoire du Cameroun. Ce passé où Nithap, alors jeune infirmier, est embarqué dans le tourbillon et les horreurs de la guerre civile, les combats pour "une vraie indépendance», le tout sous le «poncepilatisme des Français qui tirent les ficelles» et sur fond de rivalités entre «groupes» (non pas «tribus» insiste l'auteur). Les noms, les sigles, les événements, les personnages historiques, les dates et autres dissensions forment, pour le novice, le mboutoukou (personne peu intelligente ou illettrée), un labyrinthe dont il est difficile de s'extraire.

Emberlificoté, l'ignorant risque de se perdre. Emberlificoté mais emballé! Stupéfait par la découverte de cette terrible guerre civile de 1960 à 1970 que «les dirigeants de l'actuel Cameroun n'aiment pas qu'on [...] rappelle». Emballé par la densité (et l'architecture) du récit où la dimension romanesque et l'épaisseur des personnages (à commencer par les femmes) tiennent pleinement leur place. Emballé par ce travelling arrière sans concessions sur les responsabilités coloniales et la mascarade (sanglante) des nouveaux pouvoirs. Emballé par la langue, les langues plutôt, qui composent ce roman, les saveurs, les ingéniosités et les images que chacune transporte: medumba, nda-nda, pidgin dans ses différentes déclinaisons, camtok, camfranglais... Il y a l'efficace vivacité de «long crayons na emmerdeurs» pour «les intellectuels sont des emmerdeurs» ou la savoureuse figure poétique de «pour touabassi le mbenguetaire avec un mouna» soit, pour une fille qui chercherait «son Blanc» en perçant le préservatif, «titulariser le Parisien avec un gosse» ou «faire atterrir le pigeon voyageur». Plus sérieusement, l'importance donnée aux langues, aux cultures traditionnelles ou à la redécouverte de l'alphabet bamiléké révèlent, notamment aux plus jeunes, ce «monde invraisemblable», objet de "fierté» et possibilité de fortifier «son âme».

Empreintes de crabe évoque l'exil camerounais, dans sa version bamiléké: les surprises que réservent la société américaine; les réseaux sociaux qui relient «au pays»; la vie communautaire et ses Mandjo, réunions traditionnelles qui sont 
l'occasion de se retrouver et d'organiser la vie en exil; les causes de l'émigration, qui, une génération plus tard, n'ont pas changé: «Biya [«l'encore président»] gâche tout [...]. Ce pays est dans la watarout» (" égout», la «watarisation du pays», c'est sa transformation en un égout, un foutoir). Mais quand l'Ulysse camerounais revient visiter son Ithaque des tropiques, il n'est pas reconnu pour ce qu'il était. Il est devenu «l'Américain », un tiroir-caisse pour factures ou rançons, un sésame pour ouvrir toutes les portes (visa ou inscription universitaire). L'odyssée est à réécrire. Ne serait-ce que pour Marie.

M. H.

Voici un récit surprenant sur une expérience vraie, réelle, vécue. Accueillir un migrant chez soi, au sein de sa famille, c'est non seulement faire preuve de générosité ou être à l'écoute de l'Autre, c'est savoir ce qu'on veut réellement: "écrire ou accueillir, il faut choisir». C'est surtout s'adapter à l'autre: «Si Reza vient vivre à la maison, alors il faut que la maison, elle aussi, soit prête à vivre avec Reza. » C'est se poser des questions sur ses propres valeurs, ses engagements. C'est les mettre à l'épreuve, car accueillir est «un voyage joyeux». 